\title{
Anylogic Simulation-based Research on Emergency Organization of Mass Passenger Flow in Subway Station after Events
}

\author{
Yan Xing*, Shuang Liu and Huiwen Wang \\ Beijing Jiaotong University, Beijing 100044, China \\ ${ }^{*}$ Corresponding author
}

\begin{abstract}
The sudden mass passenger after social events can make huge impact on the normal operation of rail transit station. This paper mainly studies on the influence of mass passenger flow after special events on the passenger organization of the station nearby. Based on the investigation of station facilities and passenger flow data, this paper compares and analyzes the characteristics of passenger flow and measures of passenger organization on weekdays and the activity days. The station facilities and pedestrian movement simulation models are built using Anylogic. According to the congestion level and service level standard, this paper describes the influence of mass passenger flow after special events on the subway station. Then the optimized measures on operational organization are put forward to simulate and compared with simulation platform. Considering the different characteristics in different activities, we grade the impact of the events with different attendance on the subway stations from the aspect of congestion. Finally the optimized joint measures on operational organization for different impact levels are put forward by constructing an effective communication management between the venues and the subway stations.
\end{abstract}

Keywords—urban traffic; operation organization; Anylogic; mass passenger flow after events; subway station

\section{INTRODUCTION}

As urban rail transit network develops rapidly and its proportion in transportation increases, urban rail transit has become an important transportation mode for citizens' daily travel. The improvement of people's living standards has led to an increase in various types of large-scale activities, which has caused the urban rail transit system to face a sudden increase in passenger flow. When the subway station is in a mass passenger flow condition, there may be problems such as congestion and prolonged waiting time in the station. This puts a lot of pressure on the operation and organization of the urban rail transit. Therefore, the mass passenger flow organization is very important in the operation and management of the subway station. In particular, urban rail transit stations that are adjacent to large-scale event venues generally suffer from the impact of mass passenger flow after the events. Therefore, it is of great significance to study the method of operation organization and contingency plans for subway stations with large passenger flow after events, which can provide certain theoretical support for the operation organization and evacuation of large passenger flow.
Current research on mass passenger flow management and emergency evacuation of dangerous situations in urban rail transit are relatively complete. Their main research objects are the large passenger flow of the subway itself or the treatment of emergencies. However, there are few major issues particularly for large passenger flow causing by large-scale event. Taking the Capital Stadium in Beijing and its nearby subway station called National Library of China Station as an example, this paper investigates and analyzes the passenger flow data after an event to study the influence of the passenger flow on the operation organization of the subway station and uses Anylogic to simulate the situation of the passenger flow in subway station under different attendance conditions of the stadium. At last, different grades of mass passenger flow linkage operation organization methods are proposed.

\section{MASS PASSENGER FLOW INFLUENCING FACTORS AND SERVICE LEVEL EVALUATION SySTEM OF RAIL TRANSIT}

\section{A. Mass Passenger Flow Influencing Factors}

The situation of mass passenger flow refers to the flow of passengers arriving at a certain period of time that exceeds the flow of passengers that can be carried by the station's normal passenger transportation facilities or passenger organization measures. The main reasons for the mass passenger flow in urban rail transit are morning and evening peaks on weekdays, large-scale events and holidays[1]. There are many factors that affect the evacuation of mass passengers. The first is the scale of passenger flow. When the number of inbound passengers per unit time increases rapidly, and the probability of inducing a large number of passengers to delay will be greater, which makes it more difficult to evacuate mass passengers. At the same time, the evacuation of mass passengers flow is also affected by the composition of passengers. The difference in the proportion of passengers holding Metro Cards, passengers using one-way tickets, and passengers carrying large items also affect the number of passengers entering the platform floor per unit time and determine the bottleneck of evacuation process of large passenger flow. In addition, the architecture of the station will also affect the operation and organization measures of large passenger flow. The layout of station platform and hall and the placement of equipment in the non-payment area in each station are different. Therefore, organization measures and evacuation methods in the face of large passenger flow are different. 


\section{B. Service Level Evaluation System of Rail Transit}

In this paper, in order to study the influence of large passenger flow on the station, we analyze the passenger flow service level. Through literature reviews, according to the HCM2000 (Highway Capacity Manual), TCQSM (II) (Transit Capacity and Quality of Service Manual)[2], etc., the degree of congestion and service level evaluation criteria for key nodes in the station such as passages, gates, platforms, stairs, etc. applicable to this article are obtained. The queuing service level standard is adopted for key areas such as security inspection areas and automatic ticketing areas, as shown in Table I.

TABLE I. QUEUING SERVICE LEVEL STANDARD

\begin{tabular}{|l|l|l|l|}
\hline $\begin{array}{c}\text { Service } \\
\text { Level }\end{array}$ & $\begin{array}{c}\text { Occupancy area } \\
\text { per person(m2/p) }\end{array}$ & $\begin{array}{c}\text { Number of queuing } \\
\text { people (p) }\end{array}$ & $\begin{array}{c}\text { Velocity } \\
(\mathbf{m} / \mathbf{s})\end{array}$ \\
\hline A & $>0.7$ & $<1$ & $>1.33$ \\
\hline B & $0.3-0.7$ & $1-13$ & $0.5-1.33$ \\
\hline C & $0.2-0.3$ & $13-20$ & $0.3-0.5$ \\
\hline D & $<0.2$ & uncertain & uncertain \\
\hline
\end{tabular}

This paper uses Anylogic software to simulate the passenger flow situation of the subway station, so as to obtain the service level of each area within the station. Anylogic is a widely used tool for modeling and simulating discrete, system dynamics, multi-agent, and hybrid systems. It is widely used for pedestrian flow simulation in crowded areas such as railways, metro stations, stadiums, airports, and major events. Through the simulation, the service levels of different areas are obtained to determine the choke point position of the evacuation of passenger flow, so as to targeting provide an optimized solution.

\section{PASSENGER Flow ANAlysis OF THE CAPITAL StAdium AFTER EVENTS}

\section{A. Overview of the Capital Stadium and the National Library of China Metro Station}

The Capital Stadium is the largest gymnasium in Beijing with the most functions and the widest range of applications. It can accommodate 18,000 people and has the ability to hold various large-scale events. The National Library of China Metro Station adjacent to the Capital Stadium is located on the northwest of the Capital Stadium, with a straight-line distance of only $300 \mathrm{~m}$ and a walking distance of approximately $570 \mathrm{~m}$. It is the main station for those who choose to travel by subway after events.

The National Library of China Metro Station is located at Zhongguancun South Street, Haidian District, Beijing. It is adjacent to the National Library of China and is the transfer station for the Line 4 and Line 9 of Beijing Subway. The station adopts an underground dual-island platform design and is the first subway station in Beijing to achieve transferring on the same platform. The two inner rails of the station are used for Line 9 and the two outer rails are used for Line 4 . Since Line 4 going to Tiangongyuan and Line 9 going to Guogongzhuang use the same platform, and so do the Line 4 going to Anheqiao North and the terminal of the Line 9, which achieves transferring on the same platform. As shown in Figure I.

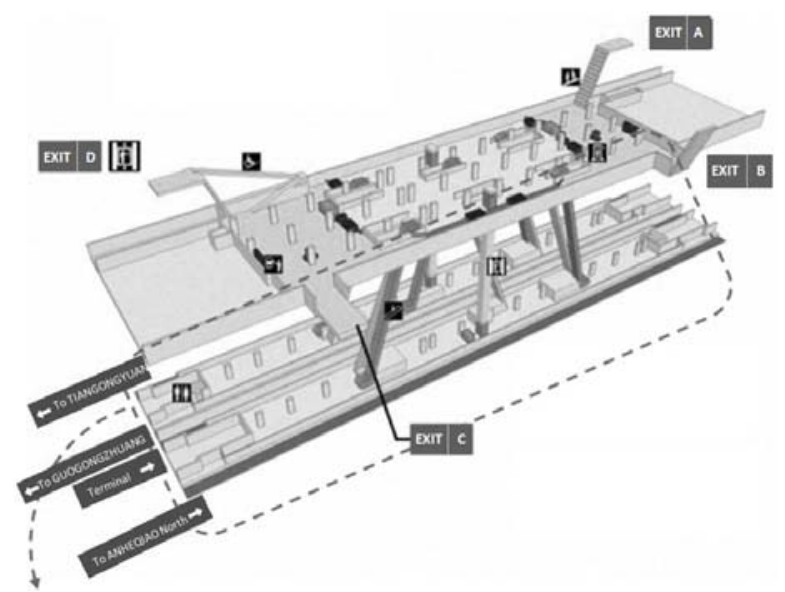

FIGURE I. THE SCHEMATIC DIAGRAM OF THE NATIONAL LIBRARY OF CHINA METRO STATION

\section{B. Passenger Flow and Organization Plan}

On March 26, 2016, Lu Han RELOADED National Tour was held at the Capital Stadium, attracting a large number of audiences to come and watch. This paper selects passenger flow data of the National Library of China Metro Station collected from the day of the concert and during the same time on weekdays. The collection sites are the A, B, C, and D entrances and important nodes such as ticketing service windows, gates and platforms of the National Library of China Metro Station. The number of people entering and leaving the station on weekdays and the activity day, ticket buying and security checking condition, the number of people gathering on the platform, the number of people getting off and transferring, and the time when the train arrived and leaved, etc. were obtained.

The change of the number of people entering the station after the concert is shown in Figure II.

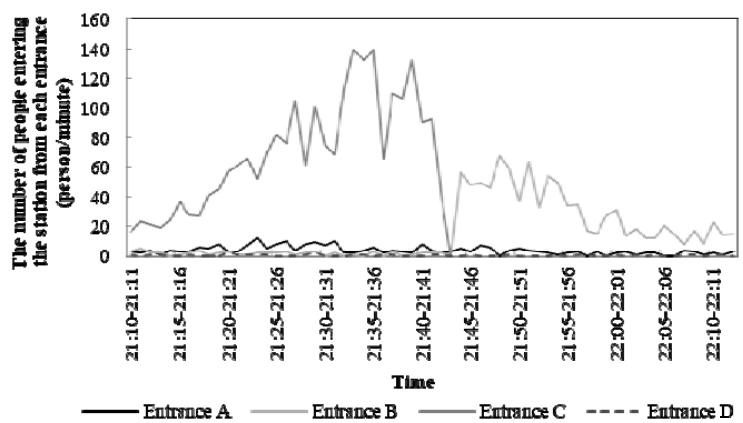

FIGURE II. THE NUMBERS OF PASSENGERS COMING INTO STATION FROM EACH ENTRANCE

At the beginning after the event ended(21:10-21:25), the number of passengers entering the station gradually increased; according to the field research, because entrance $\mathrm{C}$ of the National Library of China Metro Station is the closest to the Capital Stadium, all the passengers chose to enter the station 
from the entrance C. In the middle of the dispersion(21:2621:42), the number of inbound passengers reached a peak level; at the end of the dispersion(21:43-22:13), because the queue at entrance $C$ was too crowded, the station staff closed entrance $C$ at 21:43 and let the passengers enter the station from entrance B. The number of people entering station B increased suddenly and then gradually decreased, eventually remaining at a low level.

Through the comparison of the organization methods of the National Library of China Metro Station on the activity day and weekdays, it is found that when there were large passenger flows in the station, the station took a series of countermeasures, including increasing the number of staff inside the station, limiting the number of entrances, and increasing the number of guide staff, etc. These measures have played a role in dealing with large passenger flow. However, there are still many measures that have not been adopted, such as reducing the number of ticket services and entrance ticket gates, and increasing the number of guiding signs. There is still much room for improvement.

\section{Passenger Flow Simulation Model Construction AND SIMULATION}

\section{A. Station Model Framework Construction}

Station model construction mainly includes environment model and pedestrian model[3]. The CAD drawings of station floor and platform floor that have been drawn are imported into the software, processed and modified according to the actual facility layout, and fences, railings, labor and automatic ticket booking machines, gates, escalators and other modules are set up. The environment model is constructed as shown in Figure III.

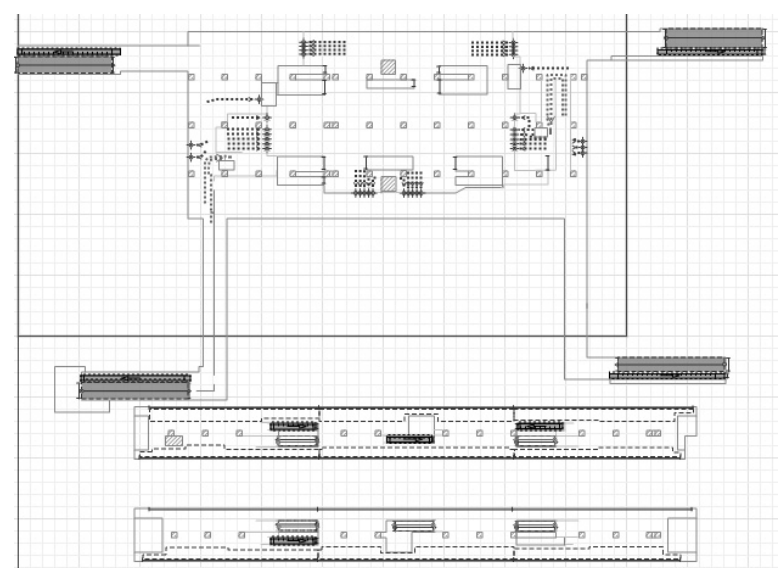

FIGURE III. THE ENVIRONMENT MODEL OF THE STATION

The construction of the pedestrian model mainly uses the pedestrian database in the software, and the construction and connection of the pedestrian module are set up according to the actual passenger flow situation. Some of the pedestrian modules are shown in Figure IV.

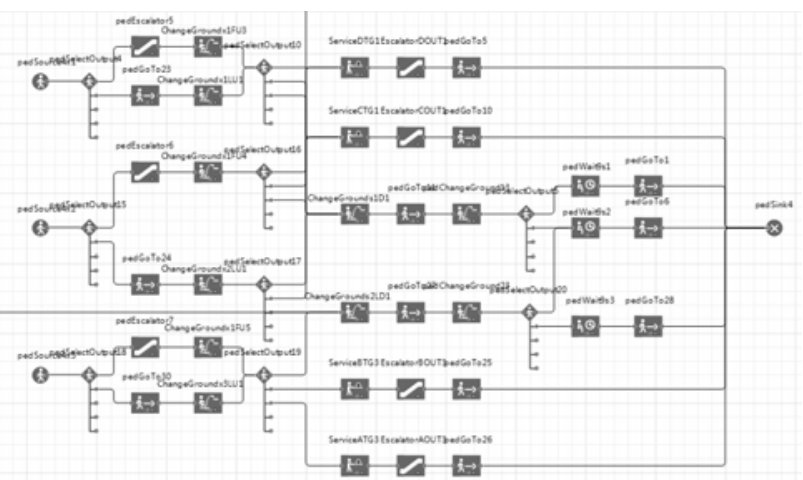

FIGURE IV. THE PROCESS OF THE PASSENGERS THAT GET OFF FROM LINE 4 ON THE EAST PLATFORM

\section{B. Passenger Data Input and Parameter Calibration}

Passenger flow input is based on the measured passenger flow data through field research, including the total number of inbound passengers in the dispersion, the number of passengers at each entrance, the service time for ticketing, the proportion of line selection, the interval between train arrivals, and the proportion of passengers choosing where to go after getting off the train.

According to the actual situation, the proportion of stations on the two sides selected by the inbound passengers is approximately 3:7, and the ratio of passengers choosing the 9th and 4 th lines on the west platform is approximately $1: 1$. The proportion of getting-off passengers who choose stairs and escalator is approximately 9:1. The time after the event is during the off-peak period, there is a long interval between trains. The departure intervals of trains on Lines 4 and 9 are approximately 6 minutes and 8 minutes respectively, which is basically the same as the departure interval on weekdays.

\section{Simulation Result Data Output and Analysis}

The simulation results on the active day are shown in Figure V and Figure VI. It can be seen from the figure that the main nodes for crowding are the security check queuing, manual ticketing and automatic ticketing queuing areas. Compared with these areas, the congestion condition of the platform waiting areas, escalators and the station hall is lighter. Therefore, this paper focuses on the density of the security inspection and the ticketing areas as the main objects to research. According to the degree of pedestrian congestion, the service level is demarcated, and then organizational measures at different levels are put forward. 


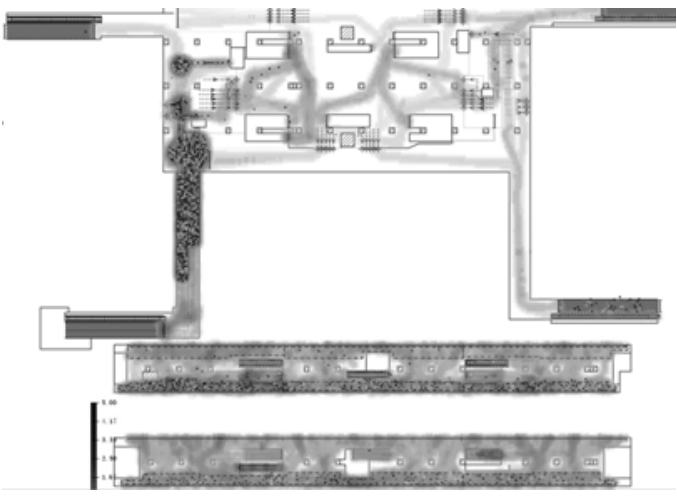

FIGURE V. THE DENSITY DISTRIBUTION IN THE STATION ON A DAY THAT HAS AN ACTIVITY

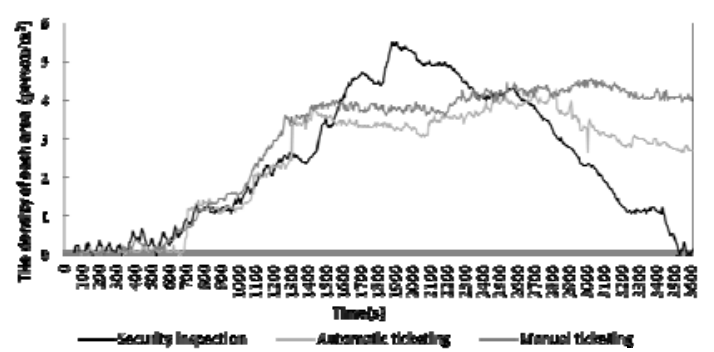

FIGURE VI. THE CHANGE OF THE DENSITY AROUND ENTRANCE C
According to the standard of service level, after the event on the day of activity, the density of passengers in the security inspection area and ticketing areas near entrance $\mathrm{C}$ quickly increased, with the highest density once reached $5.5 \mathrm{p} / \mathrm{m} 2$ (person per square meter), and the service level was at a poor level of $C$ and $D$. Afterwards, the subway station took measures to let passengers enter the station from entrance B. The security inspection area and ticketing area near entrance $\mathrm{B}$ began to appear to have too many queuing people. The service levels were at $\mathrm{C}$ and $\mathrm{D}$ levels. There was no bad service in the platform area during the entire. There were not many passengers queuing when it came to 60 minutes after the event, and the congestion at the subway station was significantly weakened.

\section{Optimization of Passenger Flow and Simulation of Different Attendance}

Through the simulation of the passenger flow on the activity day, it can be seen that the subway station's operation organization method facing the large passenger flow in the venues is not comprehensive, and the emergency measures are not implemented in time. Therefore, some optimization measures are then carried out to be taken into simulation, and the passenger flow condition in the station under different audience attendances is then simulated, so as to propose the operation organization strategy that should be taken under different circumstances.

TABLE II. THE DENSITY OF EACH AREA UNDER DIFFERENT OPTIMIZATION MEASURES

\begin{tabular}{|c|c|c|c|c|c|c|}
\hline \multirow{2}{*}{ Optimization measures } & \multicolumn{3}{|c|}{ The highest density(p/m2) } & \multicolumn{3}{|c|}{ The average density(p/m2) } \\
\hline & Security inspection & Auto-ticketing & Manual-ticketing & Security inspection & Auto-ticketing & Manual-ticketing \\
\hline $\begin{array}{l}\text { Guiding } 1 / 2 \text { passenger flow } \\
\text { to entrance B }\end{array}$ & 4.1 & 2.3 & 3.1 & 2.5 & 1.3 & 1.9 \\
\hline $\begin{array}{l}\text { Guiding } 1 / 3 \text { passenger flow } \\
\text { to entrance } \mathrm{B}\end{array}$ & 4.8 & 2.9 & 4 & 3.5 & 1.9 & 2.7 \\
\hline
\end{tabular}

The optimized organization measures mainly take into account the two forms of guiding $1 / 2$ and $1 / 3$ of the passenger flow at entrance $\mathrm{C}$ to enter from entrance $\mathrm{B}$. The simulation results are shown in Table II, and the simulation results of guiding $1 / 2$ passenger flow at entrance $C$ to enter from entrance $\mathrm{B}$ are shown in Figure VII.

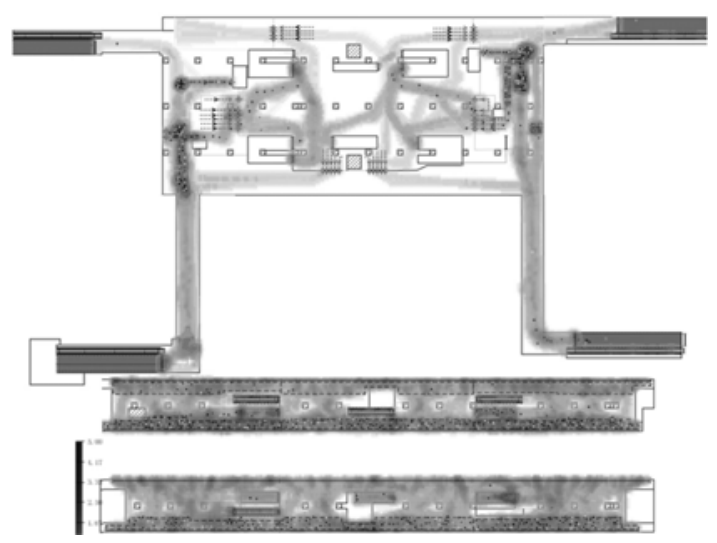

FIGURE VII. THE DENSITY DISTRIBUTION IN THE STATION UNDER GUIDE MEASURE
Simulation results show that when $1 / 2$ of the passengers are guided to enter the station from entrance $B$, congestion at the station hall floor is obviously relieved, and the service level is mostly at the B service level. At the same time, there was little change in service level at the platform floor on the activity day, and it was not overcrowded due to the increase in the number of passengers. When guiding $1 / 3$ of the passengers to enter from entrance $\mathrm{B}$, the improvement in service level near entrance $\mathrm{C}$ at the station hall floor is not obvious, and the congestion level is still at a relatively high level, which indicates that the intensity of guiding $1 / 3$ of the passengers to enter the station from other entrances cannot relieve the congestion condition obviously.

At the same time, simulations were carried out on the activities of different attendances in the stadium, with $80 \%$, $60 \%, 40 \%$ and $20 \%$ of the attendance being selected. The simulation results are shown in Table III. 
TABLE III. THE DENSITY OF EACH AREA UNDER DIFFERENT OPTIMIZATION MEASURES

\begin{tabular}{|c|c|c|c|c|c|c|}
\hline \multirow{2}{*}{ Attendance } & \multicolumn{3}{|c|}{ The highest density(p/m2) } & \multicolumn{3}{c|}{ The average density(p/m2) } \\
\cline { 2 - 7 } & $\begin{array}{l}\text { Security } \\
\text { inspection }\end{array}$ & Auto-ticketing & Manual-ticketing & $\begin{array}{l}\text { Security } \\
\text { inspection }\end{array}$ & Auto-ticketing & Manual-ticketing \\
\hline $80 \%$ & 5.1 & 3.8 & 4 & 3.9 & 2.8 & 3.3 \\
\hline $60 \%$ & 4.8 & 2.5 & 3.3 & 3.1 & 1.8 & 2.4 \\
\hline $40 \%$ & 3.8 & 2.2 & 2.5 & 2.1 & 1.2 & 1.7 \\
\hline $20 \%$ & 2.0 & 2.1 & 2.2 & 0.6 & 0.3 & 0.3 \\
\hline
\end{tabular}

According to the simulation results, it can be seen that when the attendance rate decreases, the density values of the areas also decrease, and the service level increases. Therefore, the operating organization methods should be different under different attendances of stadium.

\section{OpERATIONAL ORganization METHODS FOR THE MASS PASSENGER FLOW AFTER EVENTS}

The subway stations should have a series of emergency plans and working mechanism in the face of unexpected mass passenger flow, involving the collaboration and management of information acquisition, personnel organization, traffic organization, passenger flow control, equipment maintenance, etc[4].

Because of the different characteristics of the large-scale events held in the venues around the subway stations, the mass passenger flow after events is different. For example, attendance of large-scale events is the decisive factor in the size of the mass passenger flow after the event. If the venue can obtain the characteristics of the upcoming event in advance and share it with the subway station, the subway station will be able to formulate a corresponding emergency operation organization plan, conduct operations organization measures to guarantee passengers' safety timely and orderly, and reduce passengers' waiting time. So constructing a linkage mechanism between venues and subway stations and sharing information can effectively improve the ability of subway stations to cope with mass passenger flow after events.

Previous section has graded service levels under different attendance rates. In the case of attendance rate exceeding $80 \%$, the station should adopt first-level emergency operation organization plan. In the case of attendance rate being between $40 \%-80 \%$, the station should adopt second-level emergency operation organization plan. And in the case of attendance rate being between $20 \%-40 \%$, the station should adopt third-level emergency operations organization plan. There is no need to adopt special emergency operations organization plan when the attendance rate is less than $20 \%$. We develop alternative emergency operation organization methods for different levels of emergency plans as shown in Table IV.
TABLE IV. THE OPERATION METHODS OF DIFFERENT EMERGENCY PLAN LEVEL

\begin{tabular}{|l|c|c|c|}
\hline \multicolumn{1}{|c|}{ Level } & First & Second & Third \\
\hline Attendance rate $\mathrm{m}$ & $80 \% \leqslant \mathrm{~m} \leqslant 100 \%$ & $40 \% \leqslant \mathrm{~m}<80 \%$ & $20 \% \leqslant \mathrm{~m}<40 \%$ \\
\hline $\begin{array}{l}\text { Guiding } \\
\text { passengers to enter } \\
\text { from Entrance B }\end{array}$ & $\checkmark$ & $\checkmark$ & $\checkmark$ \\
\hline $\begin{array}{l}\text { Increasing manual } \\
\text { ticketing windows }\end{array}$ & $\checkmark$ & $\checkmark$ & $\checkmark$ \\
\hline Adding guide staff & $\checkmark$ & $\checkmark$ & $\checkmark$ \\
\hline $\begin{array}{l}\text { Adding reserve } \\
\text { fund for ticket sale }\end{array}$ & $\checkmark$ & $\checkmark$ & \\
\hline $\begin{array}{l}\text { Adding temporary } \\
\text { ticketing windows }\end{array}$ & & & $\checkmark$ \\
\hline $\begin{array}{l}\text { Adding temporary } \\
\text { guidance signs }\end{array}$ & $\checkmark$ & $\checkmark$ & $\checkmark$ \\
\hline $\begin{array}{l}\text { Using broadcast to } \\
\text { guide }\end{array}$ & $\checkmark$ & $\checkmark$ & $\checkmark$ \\
\hline $\begin{array}{l}\text { Arranging bus } \\
\text { replacement }\end{array}$ & $\checkmark$ & $\checkmark$ & \\
\hline $\begin{array}{l}\text { Adding platform } \\
\text { safe guidance }\end{array}$ & $\checkmark$ & $\checkmark$ & \\
\hline $\begin{array}{l}\text { Allocating support } \\
\text { team }\end{array}$ & $\checkmark$ & $\checkmark$ & \\
\hline $\begin{array}{l}\text { Notifying subway } \\
\text { police to assist }\end{array}$ & $\checkmark$ & & \\
\hline
\end{tabular}

\section{CONCLUSION}

The passenger flow after large-scale events will have a huge impact on the operation organization of nearby subway stations. Based on the service level grade standard, this paper studies and optimizes the influence of the passenger flow on the subway station by constructing a pedestrian simulation model. After the optimization, the maximum pedestrian density in the subway station is reduced by $40 \%$, and the service level is significantly improved. Moreover, a three-level mass passenger flow linkage and graded operation organization method is proposed for different attendance rates of venues, and different evacuation measures should be taken at different levels. This paper not only optimizes the passenger flow organization of the National Library of China Metro Station, but also provides ideas and experience for the evacuation of mass passengers for other domestic and worldwide stations.

\section{REFERENCES}

[1] MAO B H. Urban passenger transport management[M]. Beijing: China Communications Press, 2009.

[2] WANG W T. Study on Service Level and Pedestrian Facilities Capacity in Urban Rail Transit Station[D]. Beijing :Beijing Jiaotong Unibersity, 2014. 
[3] CHEN L Y, SONG R, LI Z J, et al. Simulation Study on the Layout of Metro Station Hall Facilities Based on Anylogic[J]. Journal of Transport Information and Safety, 2013, 05: 19-24.

[4] LIANG C Y. Research on capital urban transit emergency management[M]. Beijing: Qunzhong Press. 